\title{
Would you like to see a counsellor or a psychiatrist?
}

\author{
Marios Strouthos, Julia Ronder and Adrian Hemmings
}

\begin{abstract}
Mental health promotion clinic funding was introduced with the now general practice 1990 contract and has been extenstvely used to fund counsellors and stress management clinics in primary care. This funding has been withdrawn. A postal survey was conducted on all 142 general practices in East Sussex in order to assess the impact of the introduction and withdrawat of mental heatth promotion clinic funding on the employment of counsellors and on stress manogement clinics. One hundred and forty practices participated and it was found that there was an increase from 33 to 70 counsellors employed and five to 36 stress management clinics run by January 1993. Many GPs did not know what would happen to their service and if was estimated that $44(63 \%)$ of counsellors and $13(36 \%)$ stress management clinics would be lost.
\end{abstract}

\section{Background}

High levels of psychological morbidity in primary care are well established and it is also recognised that most psychological problems are treated in the primary care setting. General practitioners (GPs) are currently collaborating with a variety of nonpsychiatric mental health professionals to provide the bulk of psychiatric care in Britain. The exact role and place of the psychiatrist in interacting with the primary care team has not been clearly established and research supporting the interventions by nonpsychiatrists has generally been shown in patients with non-psychotic disorders (Wilkinson, 1988).

In the last 30 years a variety of mental health personnel have had attachments to general practice, including psychiatrists, community psychiatric nurses and clinical psychologists. However the first documentation of counsellors working in general practice was by Marsh \& Barr in 1975.

The 1990 contract for general practice in the NHS stated that health promotion and disease prevention should be part of the work of all GPs and introduced special payments for running health promotion clinics (HPCs). One specific remit was for the promotion of mental health and many practices used this for funding counsellors and stress management clinics. This funding has now been withdrawn. It was with this in mind that we conducted a postal survey in East Sussex in order to establish how HPC funding had affected the employment of counsellors in GP practices and the effect of its subsequent withdrawal.

\section{The study}

All GP practices in East Sussex Family Health Authority were sent a questionnaire that enquired about the numbers and funding of counsellors and stress management clinics from before the new GP contract in April 1990 until January 1993. Details were requested from each practice about the following.

(a) The practice characteristics including number of patients and fund-holding status. By adding up the number of patients per practice, we were able to estimate the number of patients with access to counselling during the three periods.

(b) Counselling in the practice before the new contract (Period 1), between the introduction of the new contract and June 1992 (Period 2) and January 1993 (Period 3).

(c) Supervision of counsellors and how this was funded.

(d) Stress management clinics: whether they were established before or after the new contract and who ran them during these two periods.

(e) Future plans for mental health promotion clinics.

Non-respondents were followed up by a telephone survey. Details were obtained from $140(98 \%)$ out of the 142 practices. 


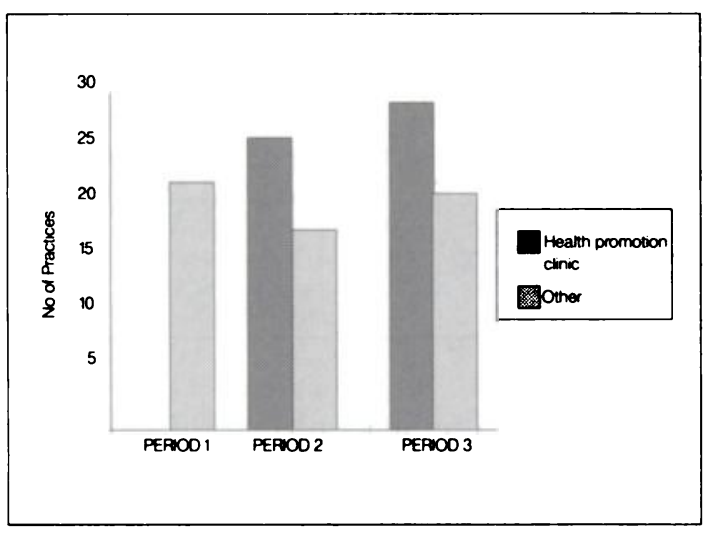

Fig. 1. Pattern of funding over three time perlods

\section{Findings}

\section{Practice characteristics}

The mean number of patients for practices which had a counselling service was 6,847 and for practices without counsellors was 4,474, indicating that it was the larger practices which tended to have a counselling service. There were four practices who had fundholding status.

\section{Changes in counselling services}

By January 1993, there was an increase from five to $\mathbf{3 6}$ stress management clinics and from 33 to 70 counsellors employed in $\mathbf{5 0}$ practices, virtually doubling the number of patients with access to such a service, from 155,000 to 338,000 (from an estimated total population of 759,712). This had become possible as these counsellors had been funded by health promotion clinic monies either directly for counselling sessions or for conducting stress management clinics. The pattern of funding over the three time periods can be seen in Fig. 1.

\section{Supervision}

Of the $\mathbf{5 0}$ practices which had a counselling service, seven $(14 \%)$ were unaware if their counsellors were supervised and $20(40 \%)$ stated that their counsellors had no supervision.

\section{Stress management clinics}

There were 36 practices which had stress management clinics. There were six clinics before the new contract, three of which were run by CPNs. Post new contract, ten (28\%) were run by GPs, seven (19\%) by practice counsellors and six (16\%) by CPNs. Other clinic leaders included nurses, health visitors, psychologists, a psychiatrist and an occupational therapist.

\section{Future plans for mental health promotion} clinics

With the withdrawal of health promotion clinic funding, most GPs said that they were left uncertain as to what to do next. Potentially 44 $(63 \%)$ of the 70 counsellors and $13(36 \%)$ of the 36 stress management clinics were to be lost after July 1993. The East Sussex Family Health Services Authority is attempting to maintain the level of employment at Period 3; however this will be funded from staff development money for which counselling has only medium priority for limited funds.

\section{Comment}

Our results show clearly that there was a change in the number of counsellors and stress management clinics available in primary care following the creation of the mental health promotion clinics (MHPCs). The survey also indicated that the majority of these new services were to be lost unless alternative funding was located. One ingredient missing from the above recipe was fund-holding. At the time of the survey only four out of the 142 practices had fund-holding status. This has, of course, changed dramatically since April 1993 and by April 1994 there were to be 49 fund-holding practices.

We now live in the new era of the purchaser/ provider system and GPs are the main potential purchasers. If they have found counselling and stress management costeffective, in the future they may choose to pay for it out of their own budgets. What effect will this have on psychiatric services? In this two year experiment the government gave GPs a taste of free counselling and stress management and yet no comprehensive evaluation of the MHPCs, funded by health promotion monies, has been completed. This means that neither the positive aspects nor the 
problems have been specifically identified or addressed. Researchers have written about the many benefits of counselling in primary care, including GPs greatly valuing the direct avallabllity of a counsellor on the premises (Wayndenfeld \& Wayndenfeld, 1980). Counselling has also shown to be an effective alternative to the prescribing of psychotropic medication (Gath \& Catalan, 1986) and it can lead to improved social functioning (Balistrieri et al, 1988).

However, we feel that it is important to highlight some of the problems associated with counselling in primary care. The training of counsellors is variable and there is no minimum amount of training required to work in general practice. A post diploma course is currently being developed by the Counselling in Primary Care Trust. The British Association for Counselling (BAC) does have a clear code of ethics, but counsellors working in general practice do not have to be members of the BAC. The BAC also has an accreditation scheme but the majority of counsellors are not accredited. This means that the patients have no guarantee that the counsellor is properly trained or receives adequate supervision. In addition, there are no clear guidelines on referral and patients with severe psychopathology may find themselves inappropriately referred to a counsellor. This may possibly place lives at risk or prolong suffering. The HPC funding provided a structure to enable counselling in primary care to develop. While there is evidence that counselling can be effective, there is concern that its unregulated growth should be treated with care. In East Sussex it allowed $43 \%$ of the population access to free counselling by way of their GP. It is reasonable to suppose that a similar pattern emerged in other counties, where HPC monies were used in a similar way. We do not know exactly what the withdrawal of HPC funding has meant to GPs, counsellors and patients. As far as the influence on psychiatric services is concerned, we shall have to wait until fund-holding and market forces take effect.

\section{Acknowledgements}

Our thanks to Counselling in Primary Care Trust for funding and all the practices who contributed to this study, especially those at 20 Sackville Road, Hove who helped in the initial piloting. We would also like to thank Kiran Reval for his help in compiling the report.

\section{References}

BALITTIER, M., WILUAMS, P. \& WILKINSON, G. (1988) Specialist mental health treatment in general practice: a meta analysis. Psychological Medictne, 18, 711-717.

GaTH, D. \& CATALAN, J. (1986) The treatment of emotional disorders in general practice. Psychological methods versus medication. Journal of Psychosomatic Research. 30. 381-386.

MARSH, G. N. \& BARR, J. (1975) Marrlage guldance counselling in a group practice. Joumal of the Royal College of General Practitioners, 25. 73-75.

WAYNDENFELD, D. \& WAYDENFELD, S. W. (1980) Counselling in general practice. Journal of the Royal College of General Practitioners, S0, 671-677.

Wrukinson, G. (1988) I don't want you to see a psychiatrist. British Medical Journal, 297, 1144-1145.

Marios Strouthos, Senior Registrar in Child \& Adolescent Psychiatry; Julia Ronder, Senior Registrar in Child and Adolescent Psychiatry; and Adrian Hemmings, Research Fellow, Trafford Centre for Medical Research, University of Sussex, Brighton BN1 9RY 